\title{
Deterioration and performance evaluation of photovoltaic modulesin a semi-arid climate
}

\author{
M. M. D. Afonso ${ }^{1}$,P. C. M.Carvalho ${ }^{1}$, F. L. M. Antunes ${ }^{1}$, \\ J. J.Hiluy Filho ${ }^{2}$ \\ ${ }^{1}$ Department of Electrical Engineering, ${ }^{2}$ Department of Chemical Engineering at Federal Universityof Ceará, \\ Campus ofPici, CEP: 60455-760- Fortaleza-Ceará, (Brasil). \\ Phone/Fax number: +00558533669585/74, e-mail: \\ afonsomassude@hotmail.com,carvalho@dee.ufc.br,fantunes@dee.ufc.br,hiluy@ufc.br
}

\begin{abstract}
PV modules are the most reliable component of a photovoltaic (PV) system. This supposed reliability leads the modules to have a warranty of up to 25 years. With the increasing insertion of PV in the energetic matrix, it is necessary to evaluate and guarantee the reliability of this source. This paper presents an evaluation of degradation in PV modules installed 15 years ago on the roof of the Department of Electrical Engineering, Federal University of Ceará, Brazil. This evaluation uses two methods: visual inspection and analysis to measure degradation degree in electrical properties of the modules. Maximum power $\left(\mathrm{P}_{\mathrm{MPP}}\right)$; Current at the maximum power point $\left(\mathrm{I}_{\mathrm{MPP}}\right)$; Voltage at the maximum power point $\left(\mathrm{V}_{\mathrm{MPP}}\right)$; Short circuit current $\left(\mathrm{I}_{\mathrm{SC}}\right)$ and Open circuit voltage $\left(\mathrm{V}_{\mathrm{OC}}\right)$ are measured using a power curve tracer and compared with manufacturers data. Visual analysis show that delamination and discoloration are the degradations found in most of the modules. Considering the electrical parameters, a MPP reduction of $30 \%$ was found.
\end{abstract}

\section{Keywords}

Photovoltaic modules, Degradation, Reliability, Lifetime.

\section{Introduction}

Constant changes in oil prices and environmental impact resulting from the use of fossil fuels has led to increasing participation of renewable energy sources worldwide.

Among the renewable energy technologies, photovoltaic (PV) has shown a significant increase in the global energy matrix[1]. According to the European Photovoltaic Industry Association (EPIA), at least $38.4 \mathrm{GW}$ in PV have been installed worldwide in 2013, a record mark for the technology[2]. Currently, the world-installed capacity is around $138.9 \mathrm{GW}$.

With such insertion in the energy matrix, PV generation can be considered economical and reliable only if the PV modules operate reliably having a lifetime of 25 - 30 years. Brazilian semi-arid climate provides ideal conditions for PV electricity production due to the high irradiation values throughout the year. However, the evaluation of the cells performance exposed to semi-arid climatic conditions should be performed to verify the development of possible damages.
Degradation in PV modules means a gradual deterioration of the component or system characteristics that can affect the ability to operate within the permitted tolerances criteria. Manufacturers consider a degraded PV module when the output power reaches a level below $80 \%$ of the nominal condition [3]. The PV modules performance can be compromised by several factors, such as temperature, humidity, radiation and mechanical shock [4]. Each of these factors can cause various types of degradation. The international standard IEC 61215 establishes the parameters for determining the modules degradation and performance. The tests include visual detection of defects in insulation and leakage currents [5].In this way, this paper aims to detect and evaluate the degradation of the electrical characteristics $\left(\boldsymbol{I}_{\boldsymbol{S C}}, \boldsymbol{V}_{\boldsymbol{O C}}\right.$, and $\left.\boldsymbol{P}_{\boldsymbol{M P P}}\right)$ and to identify by a visual inspection which types of degradation are present in PV modules installed ca. 15 years ago in Fortaleza, Brazil.

\section{Materials and Methods}

Fig. 1 shows the PV modules under investigationon the roof of the Electrical EngineeringDepartment, at the Federal University of Ceará, Fortaleza, Ceará, Brazil.The plant was installed in 1998 with a lifespan of 25 years under warranty.

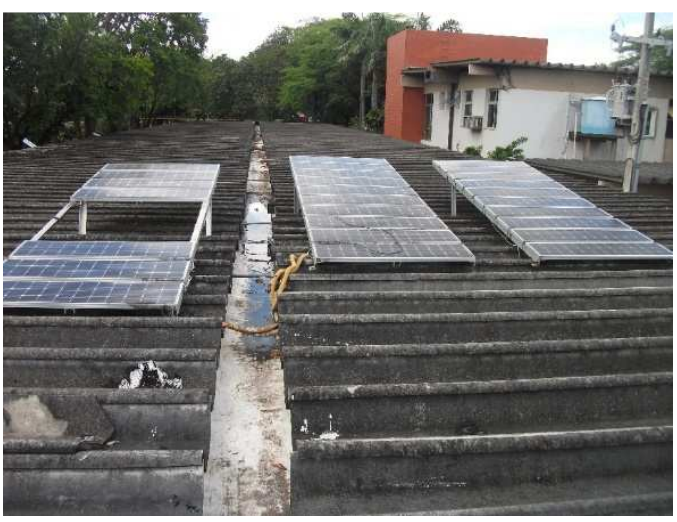

Fig. 1.Layout of the PV modules under investigation. 
The two rows of the right side (Fig. 1) are composed of 10 modules connected in parallel at each five modules. The left row shows seven modules connected individually. In this study, visual analysiswas made in all modules and analysis of the electrical parameters focused on the row withseven modules. Each of these modules consists of 36 monocrystalline silicon cells with $1293 \mathrm{~mm}$ in length, a width of $392 \mathrm{~mm}$ and $34 \mathrm{~mm}$ thick. The module electrical characteristics are given in Table I.

Table I. - Module electrical parameters

\begin{tabular}{|c|r|}
\hline \multicolumn{2}{|c|}{ PV MODULE S55 } \\
\hline Maximum power $\left(\mathrm{P}_{\mathrm{MPP}}\right)[\mathrm{W}]$ & 55.00 \\
\hline Current at the maximum power point $\left(\mathrm{I}_{\mathrm{MPP}}\right)[\mathrm{A}]$ & 3.15 \\
\hline Voltage at the maximum power point $\left(\mathrm{V}_{\mathrm{MPP}}\right)[\mathrm{V}]$ & 17.40 \\
\hline Short circuitcurrent $\left(\mathrm{I}_{\mathrm{SC}}\right)[\mathrm{A}]$ & 3.45 \\
\hline Open circuitvoltage $\left(\mathrm{V}_{\mathrm{OC}}\right)[\mathrm{V}]$ & 21.17 \\
\hline
\end{tabular}

Visual inspection and analysis of the electrical characteristics were made as described in IEC 61215 [6]. These types of analyses are very important in the evaluation of the degradation of PV modules because they describe, categorize and quantify the major forms of degradation

\section{A. Visual inspection}

The first step in a visual inspection is an examination of a PV module. The inspection allows detecting some failures and defects that can be observed visually, such as yellowing, delamination, cracks and bubbles in cells, corrosion, misalignments and burnt cells. As described in IEC 61215, visual inspection is performed under natural sunlight with a good intensity. It is recommended to inspect at several different angles to avoid errors due to the reflected image[6].

\section{B. Analysis of the electrical parameters}

The acquisition of the electrical properties of the seven modules under investigation was carried out with the use of a Mini-KLA analyser (Fig. 2).

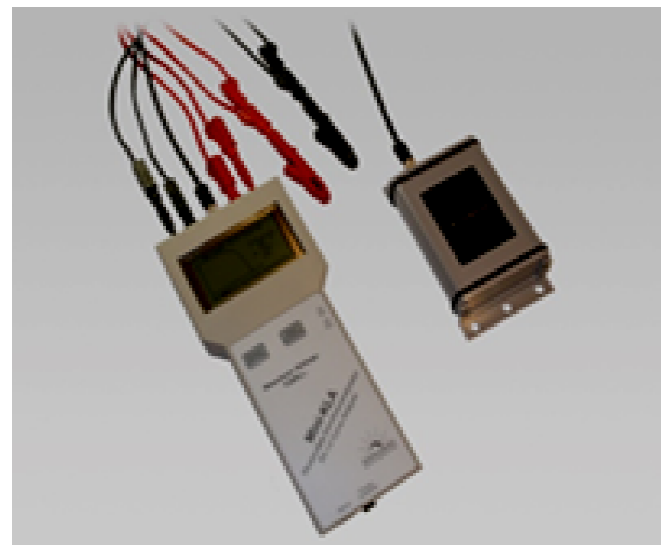

Fig. 2.Mini-KLA analyser.
This analyser is a complete measurement system to trace IV-curves of PV modules with open circuit voltages up to $120 \mathrm{~V}$ and short circuit currents up to $8 \mathrm{~A}$. The global irradiance $\left(\mathrm{W} / \mathrm{m}^{2}\right)$ and the module temperature were measured simultaneously with a reference cell attached to the analyser, so that all relevant parameters for calculating data STC (Standard Test Conditions) were considered.

Initially, the acquired data were stored in the analyser; in a second phase, data were transferred to a computer through a VGA output. The curves are visualizedwith the use of a software; Fig. 3 shows the software interface.

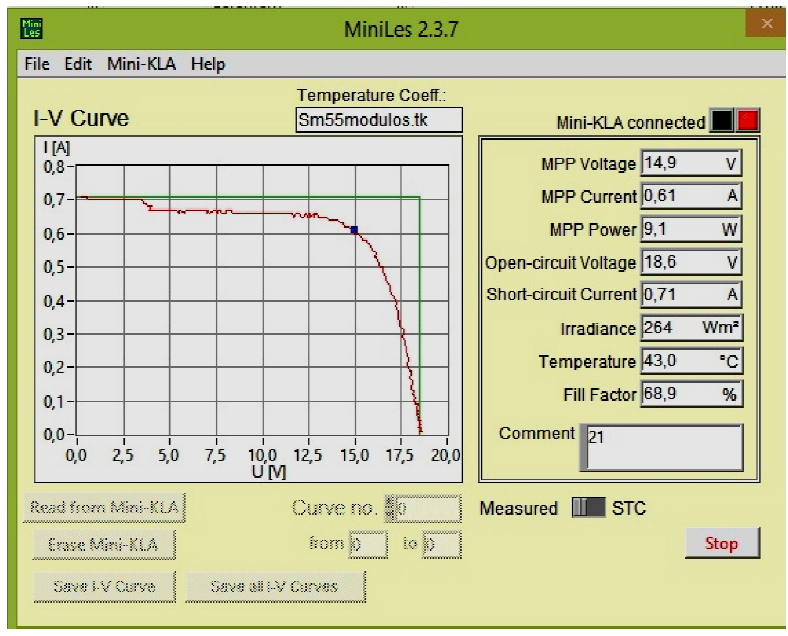

Fig. 3. Software interface with a current-voltage curve.

\section{Electrical characteristics modelling and degradation determination}

The electrical characteristics measurements (short circuit current and open circuit voltage) were corrected by mathematical modelling (equations 1, 2, 3, 4, 5 and 6), found in the literature in order to find the equivalent values in standard test conditions (STC), characterized by radiation of $1000 \mathrm{~W} / \mathrm{m}^{2}$ and cell temperature of $25^{\circ} \mathrm{C}$ [3], [7]. For that phase, initially the voltage and current were standardized using equations 1 and 2 . The values obtained from these calculations were then used to calculate the maximum output power (equation 3). Finally, to calculate the degree of degradation,equations 4,5 and 6 were used.

Equations 1 and 2 correspond to standard short-circuit current and open circuit voltage, respectively.

$$
I_{S C . s t c}=I_{S C m} *\left(\frac{1000}{G_{m}}\right)+\alpha * S *\left(T_{\text {ref }}-T_{\text {mod }}\right) r^{2}(\mathbf{1})
$$

$\boldsymbol{I}_{\boldsymbol{S C} \text {.stc }}$ represents the standard short-circuit current, $\boldsymbol{I}_{\boldsymbol{S C} \boldsymbol{m}}$ is the measured short-circuit current, $\boldsymbol{G}_{\boldsymbol{m}}$ is the measured irradiation, $\alpha$ is the current temperature coefficient, $S$ is the module surface, Tref is the temperature reference and Tmod is the module temperature [8].

$$
V_{\text {OC.stc }}=V_{O C m}+\beta * N *\left(T_{\text {ref }}-T_{\text {mod }}\right)(2)
$$


$V_{\text {OC.stc }}$ is the standard open-circuit voltage, $V_{O C m}$ is the measured open circuit voltage, $\beta$ is the voltage temperature coefficient and $\mathrm{N}$ is the number of cells per module.

$$
P_{\text {max.stc }}=I_{S C . s t c} * V_{O C . s t c} * F F(3)
$$

$P_{\text {max.stc }}$ is the standard maximum power, $I_{S C . s t c}$ represents the standard short-circuit current, $V_{O C . s t c}$ is the standard open-circuit voltageand $F F$ isthefill factor.

$$
\begin{gathered}
\Delta I_{S C}(\%)=\frac{I_{S C f}-I_{S C . s t c}}{I_{S C f}} * 100(4) \\
\Delta V_{O C}(\%)=\frac{V_{O C f}-V_{O C . s t c}}{V_{O C f}} * 100(5) \\
\Delta P_{\text {max }}(\%)=\frac{P_{\text {maxf }}-P_{\text {max.stc }}}{P_{\text {max }}} * 100
\end{gathered}
$$

$\Delta I_{S C}(\%), \Delta V_{O C}(\%)$ and $\Delta P_{\max }(\%)$ represent the percentual degradation of the short circuit current, open circuit voltage and the maximum output power, respectively. $I_{S C f}$ is the short-circuit current supplied by the manufacturer, $V_{O C f}$ is the open circuit voltage specified by the manufacturer and $P_{\max f}$ is the maximum output power specified by the manufacturer.

\section{Results}

\section{A. Visual inspection}

The main forms of degradation found in the $27 \mathrm{PV}$ modules under investigation and the frequency of occurrence of these degradations areshown in Fig. 4.

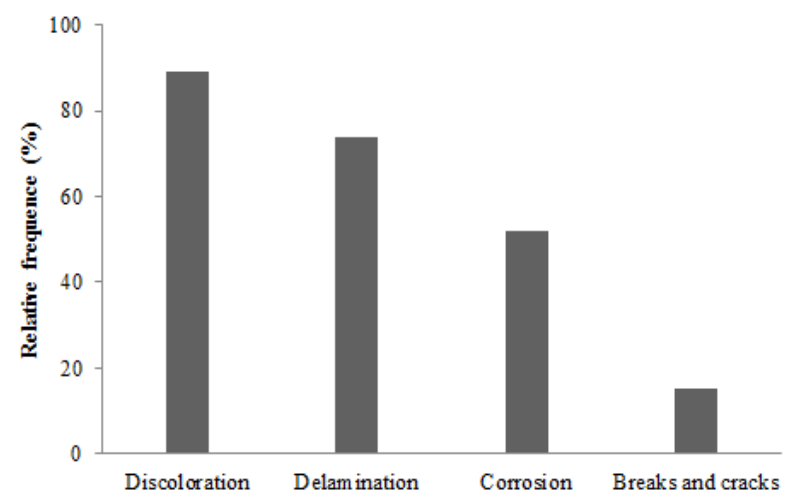

Fig.4. Frequency of degradations (discoloration, delamination, corrosion, breaks and cracks) found in the PV modules.

Discoloration was found in practically all cells, although at different rates. The delamination process occursin 20 of the 27 modules, with different intensities. In most of the cases, the effect of delamination wasfound linked with discoloration, according to Fig.5.

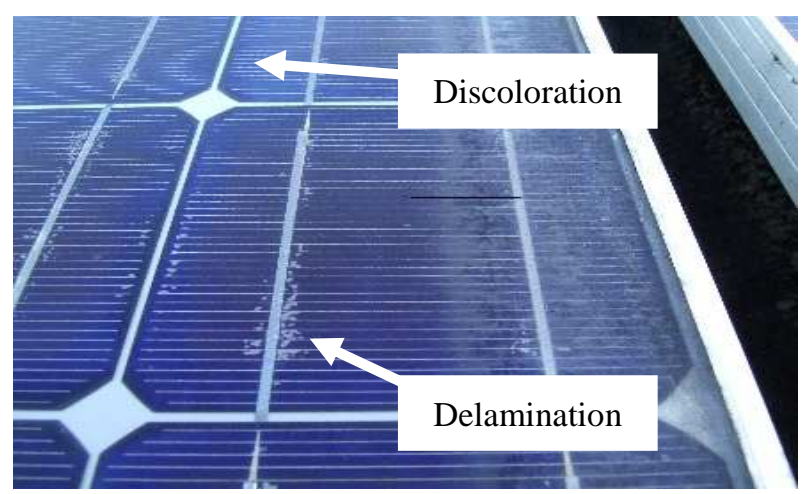

Fig.5.PV module showingdiscoloration and delamination.

These forms of degradation are a consequence of the presence of hot spots, according to Fig. 6,showing different temperatures.

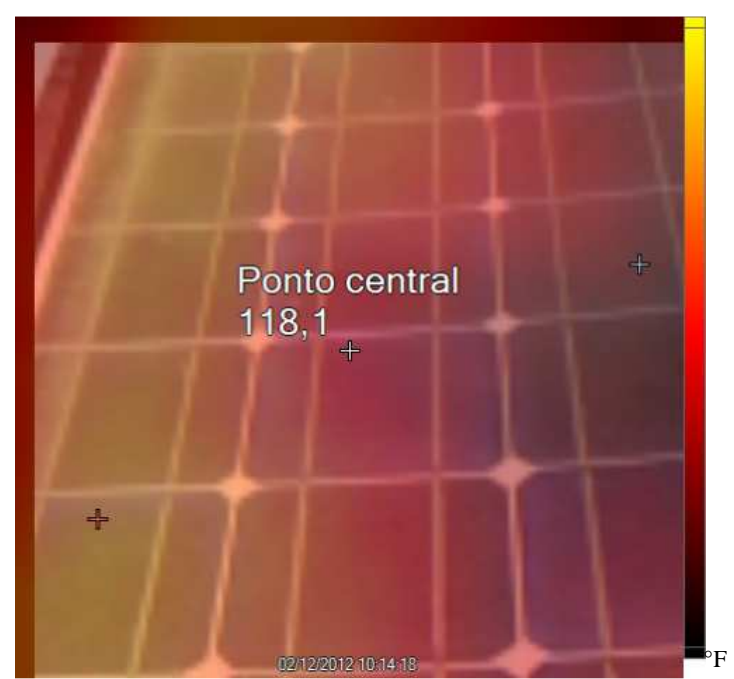

Fig. 6.Hot spots in a PV module.

Corrosion was found in almost $50 \%$ of the investigated modules. From 27 modules, three had a more intense corrosionprocess(Fig. 7).

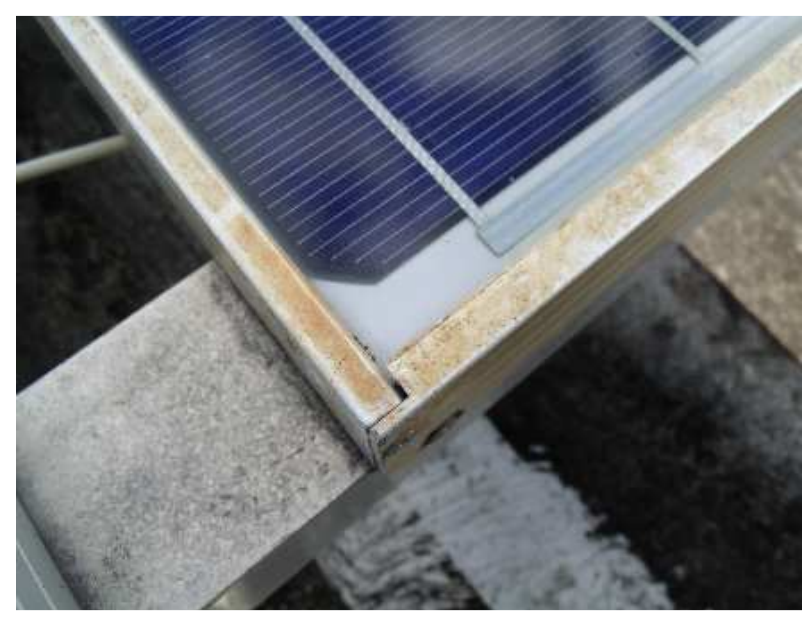

Fig.7. Corrosion of structural elements in a PV module.

The structural elements of all arrays, like details made of corrosive materials, showed advanced corrosion, with thick layers of oxidized material. Breaks and cracks were observed in only twomodules.

None of the modules showed cracks or breaks at the rear, but low corrosion was observed in the connections of the 
modules. This low corrosion, however, does not exclude the possibility of corrosion of the internal structure of the material.

\section{B. IV-curveDegradation}

All seven modules under investigationshowed an anomaly in the IV-curve near the short circuit point, as can be seen in Fig. 8. To confirm this anomaly, tests were performed with other PV modules, both monocrystalline and polycrystalline, and showed no deformation in the region, thus ruling out the possibility of having been an anomaly arising from the equipment as well as measurement errors and confirmed so that all seven modules have degradation in the IV-curve.

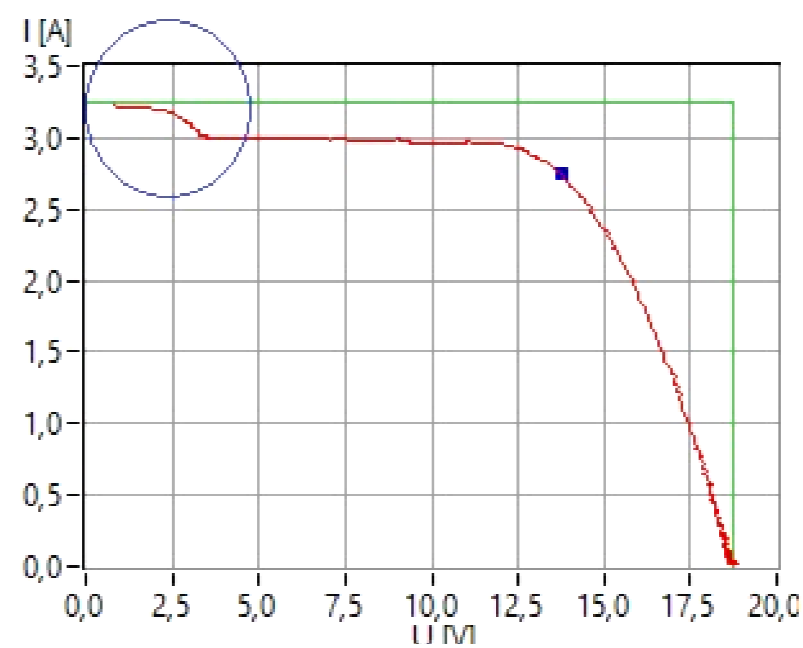

Fig.8- IV-curve anomaly found in the module 7 (M7).

This failure in this curvemay be related to the presence of hot spots on the surface of the module. The high temperatures at hot spots reduces the cell voltage and thus reduce the performance of the photovoltaic cell and eventually hamper the performance of the module [9].

\section{Analysis of the electrical properties}

Measurement of theelectrical properties of the modules in operation is affected by environmental conditions. Thus, measurements of the electrical properties done in this study were modeled in order to bring them closer to the standard test conditions used by the manufacturer in assurance testing, and then, after this, make a comparison between the values obtained by the manufacturer (Table I) and the values obtained after more than 16 years of exposure to ambient conditions.

Table II shows the degradation of the modules electrical properties, considering measurements at November6 ${ }^{\text {th }} 2014$. In the used time interval (11 am - 1 $\mathrm{pm})$, the solar intensity is approximately $1000 \mathrm{~W} / \mathrm{m}^{2}$.

Among the three analyzed electrical properties, the open circuit voltage shows less degradation than the short circuit current and power output. A module is characterized as degraded when its initial output power is below 80\% [10]. The output power degradation for the seven modules under investigationexceeded $30 \%$, characterizing them as degraded. Skoczek et al. (2009), when measured 204 modules in operation, found that high performance loss (> 20\%) were related to the fill factor loss caused by an increase in series resistance [12].

Table II. - Electrical parameters degradationinseven PV modules.

\begin{tabular}{|c|c|c|c|c|c|c|c|}
\cline { 2 - 8 } \multicolumn{1}{c|}{} & M1 & M2 & M3 & M4 & M5 & M6 & M7 \\
\hline$\Delta P_{\text {máx }}$ & 35.48 & 33.08 & 35.48 & 34.65 & 35.75 & 35.55 & 31.52 \\
\hline$\Delta I_{S C}$ & 12.73 & 12.66 & 12.73 & 13.35 & 12.56 & 12.68 & 11.58 \\
\hline$\Delta V_{O C}$ & 9.41 & 8.98 & 9.41 & 8.63 & 8.05 & 8.76 & 8.68 \\
\hline
\end{tabular}

This degradation of the electrical properties can be related to the high delamination index, discoloration and corrosion shown in visual analysis. In addition, the power degradation is also related to the fill factor, that showed very low values when compared to references found in the literature even in times of high irradiance[11].Ndiaye et al. (2014) also obtained similar results when analyzing the degradation of PV modules and related degradation of power with decreasing fill factor[13].

\section{Conclusion}

There was visual degradation and relative differences between the electrical parameters of the PV modules supplied by manufacturers and analyzed after at least 16 years of exposure in a tropical environment. The output power characteristic has the highest degradation level for all photovoltaic modules under investigation.

\section{Acknowledgement}

FUNCAP - Ceará's Foundation for Scientific and Technological Development Support for the scholarship given to the first author.

\section{References}

[1] D. C. Jordan and S. R. Kurtz, "Photovoltaic Degradation Rates - an Analytical Review," no. October 2011, pp. 12-29, 2013.

[2] D. E. Carlson, R. Romero, F. Willing, D. Meakin, L. Gonzalez, R. Murphy, H. R. Moutinho, and M. AlJassim, "Corrosion effects in thin-film photovoltaic modules," Prog. Photovoltaics Res. Appl., vol. 11, no. 6, pp. 377-386, Sep. 2003.

A. Ndiaye, A. Charki, A. Kobi, C. M. F. Kébé, P. a. Ndiaye, and V. Sambou, "Degradations of silicon photovoltaic modules: A literature review," Sol. Energy, vol. 96, pp. 140-151, Oct. 2013.

G. Oreski and G. M. Wallner, "Evaluation of the aging behavior of ethylene copolymer films for solar applications under accelerated weathering conditions," Sol. Energy, vol. 83, no. 7, pp. 1040-1047, Jul. 2009.

[5] V. Sharma and S. S. Chandel, "Performance and degradation analysis for long term reliability of solar 
photovoltaic systems: A review," Renew. Sustain.

Energy Rev., vol. 27, pp. 753-767, Nov. 2013.

[6] M. a. Munoz, M. C. Alonso-García, N. Vela, and F. Chenlo, "Early degradation of silicon PV modules and guaranty conditions," Sol. Energy, vol. 85, no. 9, pp. 2264-2274, Sep. 2011.

[7] A. Cronin, S. Pulver, D. Cormode, D. Jordan, S. Kurtz, and R. Smith, "Measuring degradation rates of PV systems without irradiance data," 2013.

[8] A. Ndiaye, C. M. F. Kébé, P. a. Ndiaye, A. Charki, A. Kobi, and V. Sambou, "A Novel Method for Investigating Photovoltaic Module Degradation," Energy Procedia, vol. 36, pp. 1222-1231, Jan. 2013.

[9] A. H. Alami, "Effects of evaporative cooling on efficiency of photovoltaic modules," Energy Convers. Manag., vol. 77, pp. 668-679, 2014.

[10] A. Charki and D. Bigaud, "Accelerated degradation testing of a photovoltaic module," 2014.

[11] T. Kojima and T. Yanagisawa, "The evaluation of accelerated test for degradation a stacked a-Si solar cell and EVA films," Sol. Energy Mater. Sol. Cells, vol. 81, no. 1, pp. 119-123, Jan. 2004.

[12] a Skoczek, T. Sample, E. Dunlop, and H. Ossenbrink, "Electrical performance results from physical stress testing of commercial PV modules to the IEC 61215 test sequence," Sol. Energy Mater. Sol. Cells, vol. 92, no. 12, pp. 1593-1604, Dec. 2008.

[13] A. Ndiaye, C. M. F. Kébé, A. Charki, P. a. Ndiaye, V. Sambou, and A. Kobi, "Degradation evaluation of crystalline-silicon photovoltaic modules after a few operation years in a tropical environment," Sol. Energy, vol. 103, pp. 70-77, May 2014. 